\section{World Hepatitis Day — July 28, 2015}

July 28, 2015, marks the fifth annual World Hepatitis Day, established in 2010 by the World Health Organization to increase awareness and understanding of viral hepatitis. Millions of acute hepatitis infections occur each year, and approximately 400 million persons are living with chronic hepatitis $\mathrm{B}$ or hepatitis $\mathrm{C}(1)$. An estimated 1.4 million persons die each year from the various forms of viral hepatitis (1). The theme of this year's World Hepatitis Day is "Prevent Hepatitis. Act Now." Key messages will focus on risks, safe injection practices, vaccination, and testing and treatment.

This issue of $M M W R$ includes a report describing the launch of a nationwide hepatitis $\mathrm{C}$ elimination program in Georgia, a country with a high burden of hepatitis C. The initial phase of the program is focused on increasing access to affordable diagnostics, free treatment of persons with severe liver disease who are at highest risk for hepatitis C-related morbidity and mortality with new curative regimens, and building capacity to achieve program goals of prevention of transmission and elimination of disease. Georgia's program might provide information and experience that can inform similar efforts in other parts of the world.

A second report summarizes viral hepatitis surveillance and outbreak data from a national surveillance system in India for epidemic-prone diseases. This report sheds light on the burden and epidemiology of acute viral hepatitis in India, particularly hepatitis A and E, and highlights the important role that routine hepatitis surveillance can play in guiding prevention efforts.

Additional information about World Hepatitis Day is available at http://worldhepatitisday.org. Resources for health professionals are available at http://www.cdc.gov/hepatitis.

\section{Reference}

1. World Health Organization. Hepatitis. Geneva, Switzerland: World Health Organization; 2015. Available at http://www.who.int/hiv/ topics/hepatitis/hepatitisinfo/en.

\section{Launch of a Nationwide Hepatitis C Elimination Program - Georgia, April 2015}

Kiren Mitruka, $\mathrm{MD}^{1}$; Tengiz Tsertsvadze, $\mathrm{MD}, \mathrm{PhD}^{2}$; Maia Butsashvili, $\mathrm{MD}, \mathrm{PhD}^{3}$; Amiran Gamkrelidze, MD, $\mathrm{PhD}^{4}$; Paata Sabelashvili ${ }^{5}$; Ekaterine Adamia ${ }^{6}$; Mari Chokheli ${ }^{7}$; Jan Drobeniuc, $\mathrm{MD}, \mathrm{PhD}^{1}$; Liesl Hagan, $\mathrm{MPH}^{8}$; Aaron M. Harris, $\mathrm{MD}^{1}$; Tea Jiqia9 ; Ana Kasradze ${ }^{4}$; Stephen Ko, $\mathrm{MD}^{10}$; Vakhtang Qerashvili2 ; Lali Sharvadze, $\mathrm{MD}, \mathrm{PhD}^{11}$; Irina Tskhomelidze ; Valeri Kvaratskhelia ${ }^{6}$; Juliette Morgan, $\mathrm{MD}^{12}$; John W.

Ward, $\mathrm{MD}^{1}$; Francisco Averhoff, $\mathrm{MD}^{1}$ (Author affiliations at end of text)

Hepatitis C virus (HCV) infects an estimated 130-150 million persons globally and results in an estimated 700,000 deaths annually from hepatocellular carcinoma or cirrhosis $(1,2)$. Georgia, a middle-income Eurasian country, has one of the highest estimated HCV prevalences in the world (3). In 2011, Georgia began offering treatment to a limited number of HCVinfected persons. Beginning in 2013, when new oral medications that can cure $>90 \%$ of $\mathrm{HCV}$ infections were licensed $(4,5)$, Georgia engaged partners to develop a comprehensive

\section{INSIDE}

758 Viral Hepatitis Surveillance — India, 2011-2013

763 Severe Illness from Methyl Bromide Exposure at a Condominium Resort — U.S. Virgin Islands, March 2015

767 Knowledge and Attitudes Regarding Antibiotic Use Among Adult Consumers, Adult Hispanic Consumers, and Health Care Providers — United States, 2012-2013

771 Notes from the Field: Death Following Ingestion of an Edible Marijuana Product — Colorado, March 2014

773 Notes from the Field: Outbreak of Cryptosporidiosis Among Veterinary Medicine Students Philadelphia, Pennsylvania, February 2015

774 QuickStats

Continuing Education examination available at http://www.cdc.gov/mmwr/cme/conted_info.html\#weekly.

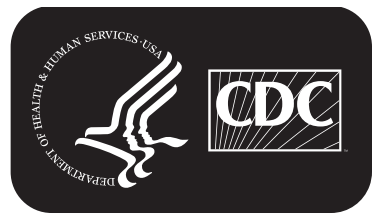

U.S. Department of Health and Human Services Centers for Disease Control and Prevention 
HCV prevention and control plan, during which the concept of elimination of HCV transmission and disease emerged. To prepare for the launch of an HCV elimination program, Georgia requested CDC's assistance to describe HCV epidemiology, evaluate laboratory and health care capacity, and conduct program monitoring and evaluation. This report describes the activities undertaken to prepare for the program, launched in April 2015, and early results of its initial phase, focused on improving access to affordable diagnostics and free curative treatment for $\mathrm{HCV}$-infected persons with severe liver disease. A national population-based serosurvey began in May 2015, and four clinical sites and their laboratories were selected as initial pilot sites; since June, three additional sites have been added. Through July 3, 2015, a total of 6,491 persons sought treatment, and 6,177 (95.2\%) initiated diagnostic work-up. Among these, 1,519 (24.6\%) completed work-up, 1,474 $(97.0 \%)$ of whom initiated treatment. Georgia is scaling up capacity to meet the demand for HCV treatment and is collaborating with $\mathrm{CDC}$ and other partners on development of a comprehensive HCV elimination plan that includes specific goals and activities needed to achieve them.

Based on the finding of $6.7 \%$ anti-HCV seroprevalence in a survey in Tbilisi, Georgia's capital and largest city, in 2002 (3), an estimated 250,000 persons among the country's 3.7 million inhabitants might be infected with HCV. Injection drug use is a major risk factor for HCV infection (3), although unsafe injection and blood safety practices also contribute to the infection burden (๑). The prevalence of HCV infection is high among prisoners (50\%) (Georgia's Ministry of Labor, Health, and Social Affairs [MoLHSA], unpublished data, 2015), injection drug users $(50 \%-70 \%)(7)$, and persons infected with human immunodeficiency virus (HIV) (47\%) (8).

Anti-HCV serologic testing is widely available in Georgia. However, tests for RNA to identify active infection, genotyping to determine strain, and fibrosis staging to assess severity of liver disease (all necessary for clinical decision-making) are expensive and more difficult to obtain. Georgia's universal health care system requires most persons to pay out-of-pocket for $\mathrm{HCV}$ diagnosis and treatment, resulting in treatment of only 100-150 patients annually, before 2011 (MoLHSA, unpublished data, 2015). In 2011, Georgia implemented programs to increase access to $\mathrm{HCV}$ treatment with pegylated interferon and ribavirin (PEG/RBV) among HIV-coinfected persons, prisoners, and the general population (Table), which has resulted in approximately 1,685 Georgians receiving treatment to date.

In 2013, the government of Georgia requested technical assistance from CDC to develop a comprehensive HCV prevention and control strategy. CDC, MoLHSA, and other national and international partners met in 2014 and identified a national HCV seroprevalence survey and improved access to new curative $\mathrm{HCV}$ treatment as initial priorities. The potential for HCV elimination in Georgia was recognized on the basis of the absence of a nonhuman viral host, available effective diagnostics, prevention, and treatment $(9,10)$, and the country's small size and population, experience with HIV prevention and control programs, strong political will, and public support.

The MMWR series of publications is published by the Center for Surveillance, Epidemiology, and Laboratory Services, Centers for Disease Control and Prevention (CDC), U.S. Department of Health and Human Services, Atlanta, GA 30329-4027.

Suggested citation: [Author names; first three, then et al., if more than six.] [Report title]. MMWR Morb Mortal Wkly Rep 2015;64:[inclusive page numbers].

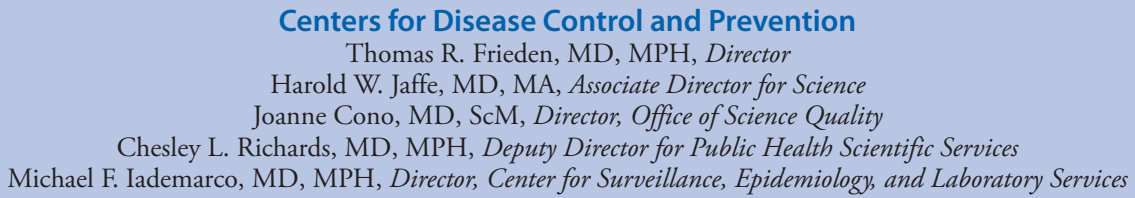

MMWR Editorial and Production Staff (Weekly)

Sonja A. Rasmussen, MD, MS, Editor-in-Chief

Charlotte K. Kent, PhD, MPH, Executive Editor

Jacqueline Gindler, MD, Acting Editor

Teresa F. Rutledge, Managing Editor

Douglas W. Weatherwax, Lead Technical Writer-Editor

Teresa M. Hood, MS, Jude C. Rutledge, Writer-Editors

\section{MMWR Editorial Board}

Timothy F. Jones, MD, Nashville, TN, Chairman

Matthew L. Boulton, MD, MPH, Ann Arbor, MI

Virginia A. Caine, MD, Indianapolis, IN

Jonathan E. Fielding, MD, MPH, MBA, Los Angeles, CA

David W. Fleming, MD, Seattle, WA

William E. Halperin, MD, DrPH, MPH, Newark, NJ
Martha F. Boyd, Lead Visual Information Specialist

Maureen A. Leahy, Julia C. Martinroe, Stephen R. Spriggs, Brian E. Wood, Visual Information Specialists Quang M. Doan, MBA, Phyllis H. King, Teresa C. Moreland, Terraye M. Starr, Information Technology Specialists

King K. Holmes, MD, PhD, Seattle, WA Rima F. Khabbaz, MD, Atlanta, GA Patricia Quinlisk, MD, MPH, Des Moines, IA Patrick L. Remington, MD, MPH, Madison, WI William L. Roper, MD, MPH, Chapel Hill, NC William Schaffner, MD, Nashville, TN 
Morbidity and Mortality Weekly Report

TABLE. Key strategies, activities, and outcomes before implementation of a nationwide hepatitis C elimination program — Georgia, 2011-2015

\begin{tabular}{|c|c|c|c|}
\hline Strategy & Period & Activity & Outcome \\
\hline \multirow[t]{4}{*}{$\begin{array}{l}\text { Improve treatment } \\
\text { access }\end{array}$} & 2011-present & $\begin{array}{l}\text { Free PEG/RBV treatment for up to } 110 \mathrm{HIV} / \mathrm{HCV} \text { co-infected persons } \\
\text { per year through Global Fund for AIDS, TB, and Malaria }\end{array}$ & 428 persons received treatment* \\
\hline & 2014-present & $\begin{array}{l}\text { Free HCV screening, diagnostics for all incarcerated persons } \\
\text { Free PEG/RBV treatment for up to } 500 \text { incarcerated persons with } \\
\text { fibrosis stage } \geq F 2 \text { (moderate disease) per year }\end{array}$ & 406 persons received treatment* \\
\hline & 2014-present & Reduced price $(60 \%)$ PEG/RBV treatment for 10,000 persons & 851 persons received treatment ${ }^{*}$ \\
\hline & 2015 & $\begin{array}{l}5,000 \text { free courses of sofosbuvir (Sovaldi), followed by } 20,000 \text { free } \\
\text { courses of ledipasvir-sofosbuvir (Harvoni) per year through Gilead } \\
\text { Science }\end{array}$ & 1,474 persons received treatment ${ }^{\dagger}$ \\
\hline $\begin{array}{l}\text { Secure political } \\
\text { commitment }\end{array}$ & 2014 & Georgian government prioritizes hepatitis $C$ control & Establishment of national HCV commission \\
\hline $\begin{array}{l}\text { Partnership } \\
\text { development }\end{array}$ & $2013-2015$ & $\begin{array}{l}\text { Engagement of international public health, academic, and industry } \\
\text { partners to strengthen } \mathrm{HCV} \text { response, with goal of elimination }\end{array}$ & $\begin{array}{l}\text { CDC technical support } \\
\text { Commitment from Gilead to provide free } \\
\text { new curative medications }\end{array}$ \\
\hline \multirow[t]{2}{*}{ Capacity assessment } & 2015 & Assessment of four clinical and eight public health laboratories & $\begin{array}{l}\text { Development of test validation panels } \\
\text { Recommendation for QA/QC plan }\end{array}$ \\
\hline & & Assessment of eight clinical sites and two prisons & $\begin{array}{l}\text { Identification of first elimination program } \\
\text { sites (i.e., total of seven sites to date, } \\
\text { including four initial pilot sites in Tbilisi) } \\
\text { Identification of critical gaps }\end{array}$ \\
\hline National planning & 2015 & $\begin{array}{l}\text { Definition steps for the initial phase of elimination program (key } \\
\text { activities and treatment protocols) }\end{array}$ & $\begin{array}{l}\text { Approval of initial activities and treatment } \\
\text { protocols }\end{array}$ \\
\hline $\begin{array}{l}\text { Monitoring and } \\
\text { evaluation }\end{array}$ & 2015 & $\begin{array}{l}\text { Expanded data system used to track care and treatment during } \\
\text { interferon access program }\end{array}$ & $\begin{array}{l}\text { Development of STOP-C data } \\
\text { management system to monitor and } \\
\text { evaluate HCV continuum of care }\end{array}$ \\
\hline Provider education & 2015 & Training of providers in $\mathrm{HCV}$ management & Ongoing \\
\hline $\begin{array}{l}\text { Defining disease } \\
\text { burden }\end{array}$ & 2015 & National seroprevalence survey & Ongoing \\
\hline Raising awareness & 2015 & $\begin{array}{l}\text { Public campaign "STOP-C" developed by Georgia's Ministry of Labor, } \\
\text { Health, and Social Affairs and partners to raise awareness for } \\
\text { diagnosis and treatment of hepatitis C }\end{array}$ & Ongoing \\
\hline
\end{tabular}

Abbreviations: $\mathrm{PEG} / \mathrm{RBV}=$ pegylated interferon and ribavirin; $\mathrm{HCV}=$ hepatitis $\mathrm{C}$ virus; $\mathrm{HIV}=$ human immunodeficiency virus; $\mathrm{QA} / \mathrm{QC}=$ quality assurance and quality control. * As of July 2015.

${ }^{\dagger}$ During April 28-July 3, 2015.

Georgia committed to building its capacity to implement an HCV elimination program. of ledipasvir-sofosbuvir (Harvoni) annually at no cost. The HCV elimination program was to be initially focused on treating $\mathrm{HCV}$-infected persons with severe liver disease and providing discounted HCV diagnostic services. Georgia requested assistance from CDC to 1) conduct a national survey to define epidemiology and disease burden, 2) assess laboratories and health care providers to identify sites with capacity to participate in the initial phase of the elimination program, and 3) monitor and evaluate the program (Table).

A stratified, multistage cluster survey designed to select a nationally representative sample of 7,000 adults, calculated based on current $\mathrm{HCV}$ prevalence estimates and an anticipated $70 \%$ response rate, was launched in six major cities (including
Tbilisi) and 10 rural regions in May 2015. Serum samples for anti-HCV antibody (and, if positive, HCV RNA and genotyping) and data on behavioral risk factors are collected during household visits. The survey will allow calculation of independent HCV prevalence estimates for the six major cities and most rural areas surveyed once analyzed by fall 2015 .

Eight clinical sites and two prisons with experience providing interferon-based treatment were assessed and scored based on six domains: leadership and governance, quality of clinical care services, health information systems/management, human resource capacity, access to necessary laboratory tests, and drug-procurement procedures. A standard World Health Organization-adapted tool was used to assess capacity at four clinical laboratories (affiliated with some of the assessed clinical 
sites) and eight public health laboratories regarding biosafety, specimen collection and accessioning, equipment and test kit use, staff competency, quality assurance and quality control (QA/QC), and reporting and communication.*

A data management system (STOP-C) was developed to collect demographic, diagnostic, clinical, and pharmacy data on patients registered for treatment, which permits data entry by health care providers as well as the Central Social Service Agency (based at MoLHSA in Tbilisi). CDC provided technical support in identifying key variables for monitoring the $\mathrm{HCV}$ continuum of care.

Four of the highest scoring clinical sites in Tbilisi and their corresponding laboratories were selected as initial pilot sites for the elimination program. All four laboratories provide point-ofcare and laboratory-based anti-HCV testing, viral load determination, and genotyping. Although one of the laboratories had International Organization for Standardization 15189 medical laboratory certification, ${ }^{\dagger}$ which specifies requirements for quality and competence in medical laboratories, all lacked external QA/QC procedures, and efforts are underway to develop such a program and validate test kits. The health care provider assessment revealed limited experience with the new HCV medications and a need for additional training and case management support. Since June 2015, three additional clinical sites with moderate scores and their laboratories in two other cities have been added to meet demands for HCV diagnosis and treatment; improvement in capacity is ongoing at these sites.

An HCV Elimination Program Treatment Inclusion Committee, consisting of clinicians, patient advocacy representatives, and media, was established to review each (de-identified) patient record to determine treatment eligibility and appropriateness of provider-recommended regimens, and to ensure transparency and equitability of access to treatment. As of July 3 , 2015, among 6,491 HCV-positive persons who sought treatment, 6,177 (95.2\%) initiated diagnostic work-up, of whom $1,519(24.6 \%)$ had completed evaluation and obtained required documentation for treatment consideration. The committee has evaluated and approved 1,474 (97.0\%) of these patients for treatment initiation, and all 1,474 have started treatment.

\section{Discussion}

The response to the initial phase of Georgia's HCV control program has been larger than that for earlier PEG/RBV access programs. Increased demand likely is the result of the availability of free, effective, well-tolerated, and curative treatment options, coupled with affordable diagnostics for HCV-infected persons with advanced liver disease, who are at greatest risk

\footnotetext{
*Additional information available at http://www.who.int/ihr/publications/ laboratory_tool.

${ }^{\dagger}$ Additional information available at http://www.iso.org/iso/catalogue_ detail?csnumber $=56115$.
}

\section{Summary}

What is already known on the topic?

Hepatitis C virus (HCV) infection is a serious health problem that affects an estimated 130-170 million persons globally and results in an estimated 700,000 deaths annually. In 2013, new all-oral, well-tolerated regimens were licensed that can cure $>90 \%$ of HCV infections. The country of Georgia has one of the world's highest estimated HCV prevalences.

What is added by this report?

In April 2015, Georgia launched a hepatitis C elimination program that will initially focus on treating HCV-infected persons who have severe liver disease with new curative regimens, providing discounted HCV diagnostics to all persons, and building capacity to eventually diagnose and treat all Georgians infected with HCV. A national serosurvey was launched in May 2015, and seven clinical sites have opened to diagnose and treat HCV. Georgia is scaling up capacity to meet the high demand for HCV treatment.

What are the implications for public health practice?

Georgia has increased access to HCV testing and treatment as part of preparatory phase of a national HCV control program with goals for the elimination of HCV transmission and disease in the country. Georgia's program can provide information and experience that will assist similar efforts in other parts of the world.

for morbidity and mortality. Additional provider training and case management support are remaining challenges. MoLHSA initially limited the number of participating sites, to ensure quality and appropriate clinical decision making; the recent addition of three new sites should reduce program delays and facilitate program expansion, and assessment of additional providers and laboratories is ongoing. Monitoring and evaluation will continue, and efforts are ongoing to develop an external QA/QC system to be used by laboratories to achieve and maintain biologic safety and quality diagnostic standards. Although HCV is a strong candidate for elimination in Georgia, many challenges exist, including the asymptomatic, chronic nature of disease, which results in diagnostic delays, and ongoing transmission in health care settings and among hard-toreach populations (e.g., injection drug users) with potential for reinfection. To address these challenges, Georgia is developing a comprehensive elimination plan that addresses advocacy and communication, surveillance (including quality diagnostics), prevention (e.g., infection control, blood safety, and harm reduction), and testing and linkage to care. ${ }^{\S}$ An international technical advisory committee is being formed to help define achievable and measurable elimination goals and indicators, and determine priority activities. Additionally, MoLHSA has

\footnotetext{
\$Additional information available at http://www.who.int/csr/disease/hepatitis/ GHP_framework.pdf.
} 
begun to implement broader HCV control activities, including a campaign to raise awareness, provision of free $\mathrm{HCV}$ testing to identify HCV-infected persons unaware of their infection status, and improved infection control practices. Georgia's elimination program can provide information and experience that will assist similar efforts in other parts of the world.

\section{Acknowledgments}

Rachel Wilson, Division of Viral Hepatitis, National Center for HIV/AIDS, Viral Hepatitis, STD, and TB Prevention, CDC; Maia Japaridze, MD, Global Disease Detection, Division of Global Health Protection, South Caucasus CDC Office, Tbilisi, Georgia; Maia Alkhazashvili, MD, Gvantsa Chanturia, PhD, Nazibrola Chitadze, Roena Sukhiashvili, Konstantin Gvetadze, MD, National Center for Disease Control and Public Health of Georgia, Ministry of Labor Health and Social Affairs; Lana Gatserelia, MD, Nikoloz Chkhartishvili, MD, Infectious Diseases, AIDS, and Clinical Immunology Research Center, Tbilisi, Georgia; Marine Karchava, MD, Hepa Lab, Tbilisi, Georgia; George Kamkamidze, MD, NeoLab, Tbilisi, Georgia; Sophia Metreveli, Mrcheveli Lab, Tbilisi, Georgia.

${ }^{1}$ Division of Viral Hepatitis, National Center for HIV/AIDS, Viral Hepatitis, STD, and TB Prevention, CDC; ${ }^{2}$ Infection Diseases, AIDS, and Clinical Immunology Research Center, Tbilisi, Georgia; ${ }^{3}$ Neolab, Tbilisi, Georgia; ${ }^{4}$ National Center for Disease Control and Public Health of Georgia, Ministry of Labor Health and Social Affairs of Georgia; ${ }^{5}$ Georgian Harm Reduction Network, Tbilisi, Georgia; ${ }^{6}$ Ministry of Labor Health and Social Affairs of Georgia; ${ }^{7}$ Open Society Foundation, Tbilisi, Georgia; ${ }^{8} \mathrm{CDC}$ Foundation; ${ }^{9}$ State Regulation Agency for Medical Activities, Ministry of Labor Health and Social Affairs of Georgia; ${ }^{10}$ Boston University School of Public Health;

${ }^{11}$ Georgian French Joint Hepatology Clinic, Tbilisi, Georgia; ${ }^{12}$ Global Disease Detection, Division of Global Health Protection, South Caucasus CDC Office, Tbilisi, Georgia.

Corresponding author: Kiren Mitruka, kmitruka@cdc.gov, 404-639-3488.

\section{References}

1. World Health Organization. Hepatitis fact sheet no. 164. April 2014. Available at http://www.who.int/mediacentre/factsheets/fs164.

2. GBD 2013 Mortality and Causes of Death Collaborators. Global, regional, and national age-sex specific all-cause and cause-specific mortality for 240 causes of death, 1990-2013: a systematic analysis for the Global Burden of Disease Study 2013. Lancet 2015;385:117-71.

3. Stvilia K, Tsertsvadze T, Sharvadze L, et al. Prevalence of hepatitis C, $\mathrm{HIV}$, and risk behaviors for blood-borne infections: a population-based survey of the adult population of T'bilisi, Republic of Georgia. J Urban Health 2006;83:289-98.

4. Liang TJ, Ghany MG. Current and future therapies for hepatitis $C$ virus infection. N Engl J Med 2013;368:1907-17.

5. Webster DP, Klenerman P, Dusheiko GM. Hepatitis C. Lancet 2015;385:1124-35.

6. Zaller N, Nelson KE, Aladashvili M, Badridze N, del Rio C, Tsertsvadze T. Risk factors for hepatitis $\mathrm{C}$ virus infection among blood donors in Georgia. Eur J Epidemiol 2004;19:547-53.

7. Shapatava E, Nelson KE, Tsertsvadze T, del Rio C. Risk behaviors and HIV, hepatitis $\mathrm{B}$, and hepatitis $\mathrm{C}$ seroprevalence among injection drug users in Georgia. Drug Alcohol Depend 2006;82(Suppl 1):S35-8.

8. Chkhartishvili N, Sharvadze L, Chokoshvili O, et al. Mortality and causes of death among HIV-infected individuals in the country of Georgia: 1989-2012. AIDS Res Hum Retroviruses 2014;30:560-6.

9. Dowdle WR. The principles of disease elimination and eradication. MMWR Surveill Summ 1999;48(Suppl 1).

10. Burki T. Elimination on the agenda for hepatitis C. Lancet Infect Dis 2014; 14:452-3. 


\section{Viral Hepatitis Surveillance — India, 2011-2013}

Tripurari Kumar, $\mathrm{MPH}^{1}$; Aakash Shrivastava, $\mathrm{MD}^{2}$; Anil Kumar, $\mathrm{MD}^{2}$; Kayla F. Laserson, $\mathrm{ScD}^{3}$; Jai P. Narain, $\mathrm{MD}^{1}$; Srinivasaraghavan Venkatesh, MD ${ }^{4}$; Lakhbir S. Chauhan, DPH ${ }^{5}$; Francisco Averhoff, $\mathrm{MD}^{6}$ (Author affiliations at end of text)

The burden of viral hepatitis in India is not well characterized. In 2009, the national Integrated Disease Surveillance Programme (IDSP) began conducting surveillance across all Indian states for epidemic-prone diseases, including foodborne and waterborne forms of viral hepatitis (e.g., hepatitis A and E). Information on outbreaks of all forms of viral hepatitis, including A, B, C, and E, also is collected. This report summarizes viral hepatitis surveillance and outbreak data reported to IDSP during 2011-2013. During this period, 804,782 hepatitis cases and 291 outbreaks were reported; the virus type was unspecified in $92 \%$ of cases. Among 599,605 cases tested for hepatitis A, 44,663 (7.4\%) were positive, and among 187,040 tested for hepatitis E, 19,508 (10.4\%) were positive. At least one hepatitis outbreak report was received from 23 (66\%) of 35 Indian states. Two-thirds of outbreaks were reported from rural areas. Among 163 (56\%) outbreaks with known etiology, 78 (48\%) were caused by hepatitis E, 54 (33\%) by hepatitis A, 19 (12\%) by both hepatitis A and E, and 12 (7\%) by hepatitis B or hepatitis C. Contaminated drinking water was the source of most outbreaks. Improvements in water quality and sanitation as well as inclusion of hepatitis A vaccine in childhood immunization programs should be considered to reduce the public health burden of hepatitis in India. Efforts to decrease the proportion of cases for which the etiology is unspecified, including expanding the IDSP to support hepatitis B and C testing, might help further elucidate the epidemiology of these diseases.

India is known to have a large burden of viral hepatitis (1-4), but national surveillance data are lacking. In 2009, IDSP, operated through India's National Center for Disease Control (NCDC), became active in all Indian states (5). Weekly surveillance data on 18 epidemic-prone diseases, including viral hepatitis, are collected through this program. All 28,850 government-run primary health care centers and hospitals and 2,923 designated private facilities serve as reporting units, which collect and report data on hepatitis cases (any acute onset of jaundice) and outbreaks, and report them to district surveillance units each week. These reports are submitted as aggregate data to IDSP through a web portal (http://www.idsp. nic.in); no demographic information, risk factors, or other data are collected or reported.

The district surveillance units also investigate suspected hepatitis outbreaks (two or more epidemiologically linked cases of acute jaundice). IDSP supports testing for hepatitis A and $\mathrm{E}$, and during outbreaks, testing for hepatitis $\mathrm{B}$ and $\mathrm{C}$ also is supported. Outbreak investigation reports include a description of the affected population, number of cases and deaths, date of onset of the first case, laboratory data, information on the suspected source of the outbreak, and control measures undertaken. Hepatitis outbreaks are classified by etiology when at least one case is laboratory-confirmed and the others are epidemiologically linked. Cases are categorized as hepatitis $\mathrm{A}, \mathrm{B}, \mathrm{C}, \mathrm{E}$, or unspecified if the etiology is not determined. NCDC operates a national outbreak-monitoring call center and a national media scanning center to identify suspected outbreaks and, after investigation, also compiles them into weekly national alerts. This report summarizes an analysis of 2011-2013 national viral hepatitis surveillance and outbreak data from IDSP and weekly national alerts. Census data from 2011 were used to calculate incidence.

During 2011-2013, a total of 804,782 viral hepatitis cases were reported to IDSP. Among 599,605 (74.5\%) cases tested for hepatitis A, 44,663 (7.4\%) were positive, and among $187,040(23.2 \%)$ tested for hepatitis E, 19,508 (10.4\%) were positive. The etiology of 740,611 (92\%) reported cases was not determined (Figure 1 and Figure 2). During June-September

FIGURE 1. Number of hepatitis cases reported, number tested, and number confirmed for hepatitis A and hepatitis $E^{*}$ - India, 2011-2013

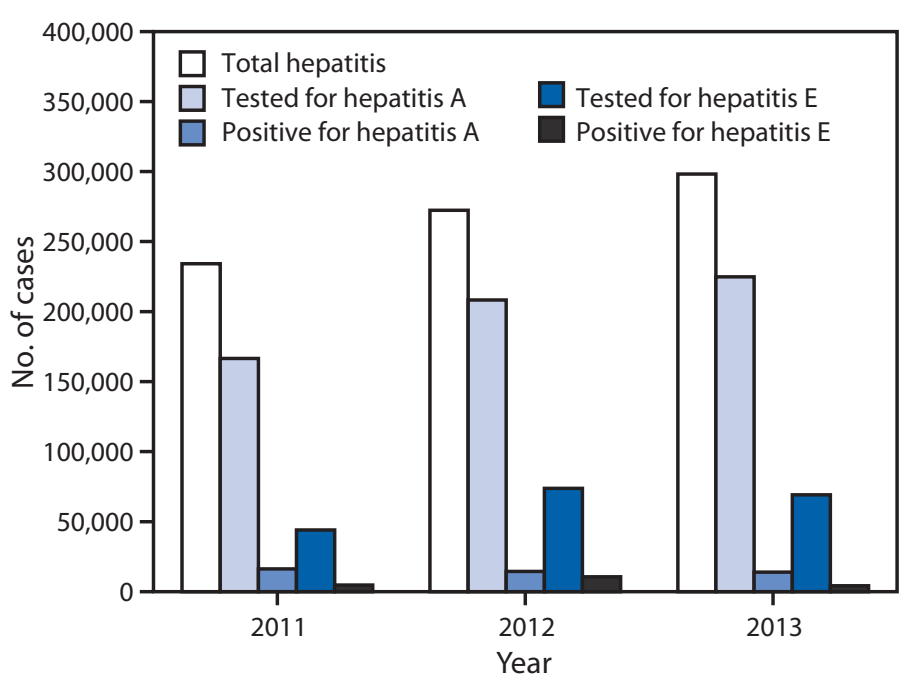

* Nos. of cases tested for hepatitis A and E are not mutually exclusive. 
FIGURE 2. Total number of hepatitis cases reported and number laboratory-confirmed as hepatitis A and hepatitis E, by surveillance weeks India, 2011-2013

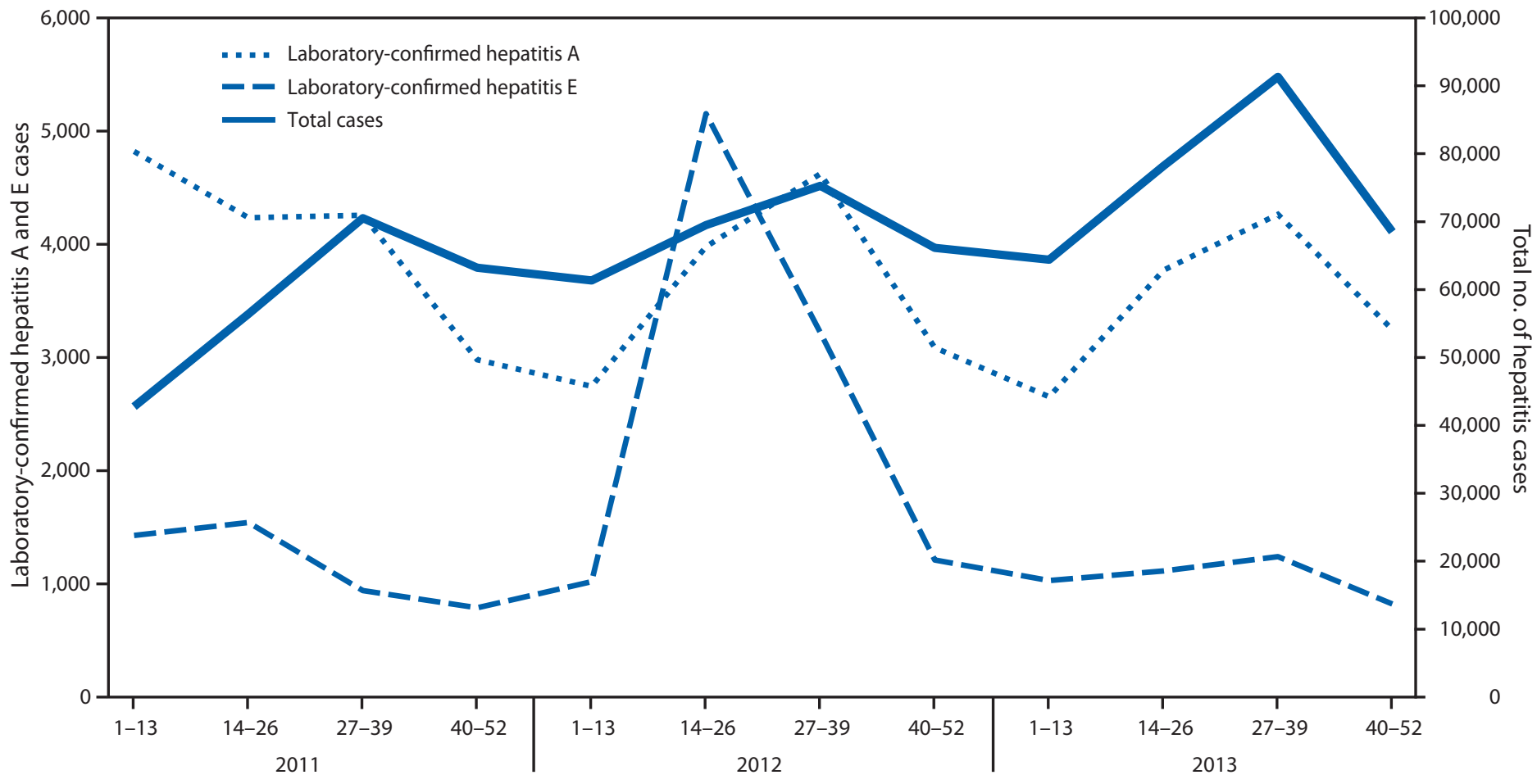

Surveillance weeks and years

of each reporting year, a $17 \%$ increase in the total number of reported hepatitis cases above baseline was observed, and laboratory-confirmed hepatitis A cases followed the same seasonal pattern with an average increase of $18 \%$ (Figure 2). During the 3-year period, eight states had average annual rates of $>50 / 100,000$ total hepatitis cases, whereas no state reported rates of $\geq 10 / 100,000$ hepatitis $A$ or $E$ cases during any year of the reporting period.

During the 3-year period, 291 hepatitis outbreaks involving 15,601 cases and $58(4 \%)$ deaths were reported to IDSP. Outbreak-related cases accounted for $1.9 \%$ of all reported hepatitis cases. Twenty-three (65.7\%) of India's 35 states reported at least one hepatitis outbreak; five states reported $>20$ outbreaks (Figure 3). More outbreaks were reported from rural areas (199 [68\%]) than urban areas (92 [32\%]); $163(56 \%)$ outbreaks were laboratory-confirmed, and, of those, most were either hepatitis E (78 [47.9\%]) or hepatitis A (54 [33.1\%]). Additionally, both hepatitis A and E were reported in 19 outbreaks, and hepatitis B or C, or both, was reported as the etiology of 12 outbreaks. Contaminated drinking water was identified as a cause for $72 \%$ (109 of 151) of the hepatitis A and E outbreaks, and was implicated in $49(38 \%)$ of the 128 outbreaks for which laboratory confirmation was not available.

\section{Discussion}

This is the first report of national viral hepatitis surveillance and outbreak data from India. Although a specific etiology was not confirmed for most reported cases, hepatitis cases and outbreaks caused by hepatitis A and E were regularly reported from most regions, and a seasonal variation in hepatitis A cases was recognized, although no seasonal pattern was observed for outbreaks. Consistent with previous reports from India $(1,2)$, unsafe drinking water was the most commonly reported cause of hepatitis A and E outbreaks, highlighting the need for improved access to clean drinking water and improved sanitation. Although IDSP does not routinely support laboratory testing for hepatitis $\mathrm{B}$ and $\mathrm{C}$, it does support testing during outbreaks, resulting in some hepatitis B and C outbreaks being detected. This finding suggests a potential benefit of including hepatitis B and C testing of nonoutbreak cases reported to IDSP to better understand the burden and epidemiology of these pathogens. The small proportion of jaundice cases tested for either hepatitis A or E that tested positive, $7 \%$ and $10 \%$, respectively, needs further investigation. The low number of laboratory-confirmed cases could be the result of misclassification of clinical cases, laboratory error, delays in testing, or large numbers of acute hepatitis that are neither A nor E. Some states with the highest reported number of outbreaks 
FIGURE 3. Number of reported hepatitis outbreaks ( $=291)$, by state - India, 2011-2013

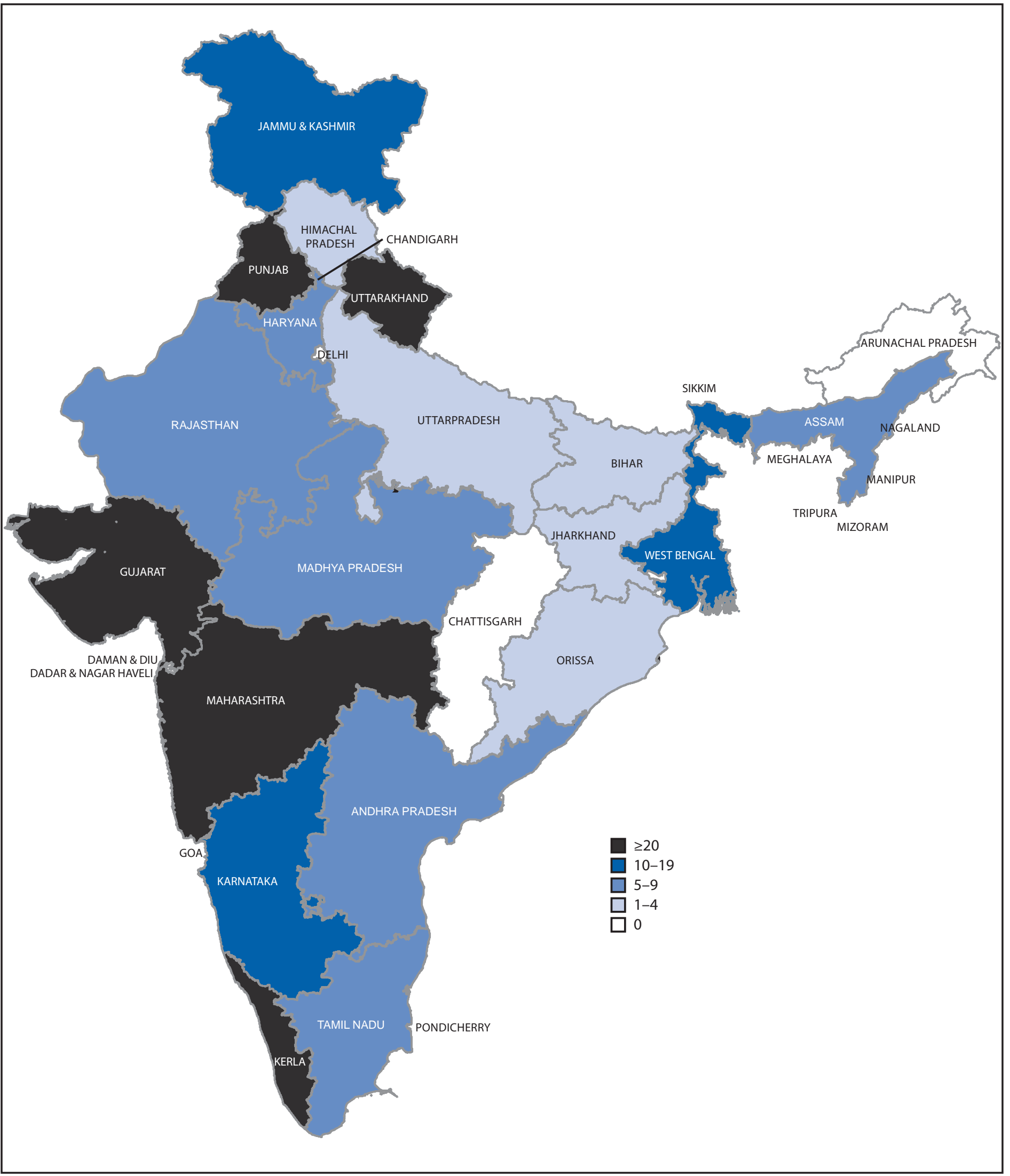




\section{Summary}

What is already known on this topic?

Hepatitis A and hepatitis E are endemic in India, and although hepatitis $B$ and hepatitis $C$ are thought to be common, national data are lacking on all forms of viral hepatitis.

What is added by this report?

The National Integrated Disease Surveillance Program, established in India in 2009, collects data on cases and outbreaks of jaundice, and supports outbreak investigations and laboratory testing for hepatitis A and hepatitis E. During 2011-2013, large numbers of hepatitis $A$ and hepatitis $E$ cases and frequent outbreaks occurred each year. Hepatitis $A$ and hepatitis $E$ outbreaks were reported throughout the country, associated with poor water quality and lack of sanitation. Cases of hepatitis $A$ appeared to follow a seasonal pattern associated with the monsoon season.

What are the implications for public health practice?

Epidemiologic and laboratory strengthening of the Integrated Disease Surveillance Program might improve understanding of the hepatitis disease burden in India because most cases were not laboratory-confirmed. Further, the large numbers of cases and outbreaks underscore the need for improvements in water quality and sanitation. Finally, collection of additional demographic and epidemiologic data on hepatitis A can inform consideration of including hepatitis $A$ vaccine in routine immunization programs.

were among those supported by the World Bank for surveillance infrastructure strengthening ( $($ ), and better surveillance in these states might account for the increased number of cases as well as outbreaks reported, rather than an actual greater number of outbreaks in these states.

Surveillance for hepatitis often underestimates the actual number of cases. Nevertheless, IDSP identified a substantial number of hepatitis cases and outbreaks during 2011-2013. The large number of hepatitis A and E outbreaks might be explained in part by the lack of adequate sewage and sanitation systems (1); defecation in open fields, which can contaminate surface drinking-water sources, remains a common practice. The large numbers of hepatitis A cases might also reflect an epidemiologic shift in the affected population in India. Hepatitis A infection during childhood often is asymptomatic and unrecognized, and typically confers lifelong immunity. With increasing age at time of infection, symptomatic cases become more common. With improved hygiene and sanitation reflecting India's improving economy, more children might escape childhood infection and remain susceptible to infection during adolescence and adulthood (7). Demographic data, including age, not currently included in IDSP, would help to better understand the epidemiology of hepatitis A in India. Such data also could be used to inform consideration of inclusion of hepatitis A vaccine in the routine immunization program.

Peaks in reporting occurred during the monsoon season (June-September) for both total cases reported and hepatitis A cases reported during each of the reporting years. This pattern suggests that most unspecified cases might be hepatitis $A$, and that there is seasonal variation in transmission of hepatitis $\mathrm{A}$, possibly related to contamination of drinking water during periods of heavy rain.

Hepatitis B and C cause substantial morbidity and mortality worldwide. Although poorly described in India, hepatitis B and $\mathrm{C}$ are thought to contribute substantially to the country's overall hepatitis burden $(3,4)$. Through IDSP, laboratory support has been steadily strengthened, and most states have at least one public health laboratory $(5,6)$; however, routine laboratory testing of suspected hepatitis cases for hepatitis B and $\mathrm{C}$ is not currently supported by IDSP. Inclusion of such testing would improve understanding of the epidemiology of hepatitis B and C and relevant risk factors. Further, surveillance for chronic hepatitis, cirrhosis, and hepatocellular carcinoma would give valuable insights into the long-term disease burden in the country (2).

The findings in this report are subject to at least four limitations. First, the finding that more hepatitis outbreaks are reported from rural than urban areas might partially be explained by greater government-sponsored health care delivery in rural areas, which might be more likely to identify and report outbreaks to IDSP. Second, the majority of reported cases were not laboratory-confirmed. Third, data were available for only a few hepatitis B and C outbreaks, limiting the use of data from those investigations. Finally, incomplete follow-up and reporting of outbreaks to IDSP might lead to an underestimation of the burden and an inadequate understanding of the epidemiology of the outbreaks.

Routine disease surveillance is a core public health function. The formation of IDSP is a major advance toward building India's public health capacity to identify and react to urgent threats and monitor disease trends. Hepatitis surveillance data obtained through IDSP can be used to monitor disease trends, identify local hepatitis outbreaks, and to evaluate the effectiveness of sanitation, safe water, immunization, and other prevention and control measures. To enhance the utility of its data, IDSP might consider introducing case-based surveillance that includes demographic and risk factor data, improving geographic representativeness of surveillance data, and increasing the proportion of cases that are laboratory-confirmed. Further, increasing laboratory capacity to include hepatitis B and C into routine testing might help identify unrecognized modes of transmission and populations at risk for infection (4). 


\footnotetext{
${ }^{1}$ India Epidemic Intelligence Service Program, National Centre for Disease Control (NCDC); ${ }^{2}$ Epidemiology Division, NCDC; ${ }^{3}$ Division of Global Disease Detection, Center for Global Health CDC India; ${ }^{4}$ Integrated Disease Surveillance Program, NCDC; ${ }^{5}$ Office of the Director, NCDC; ${ }^{6}$ Division of Viral Hepatitis, National Center for HIV/AIDS, Viral Hepatitis, STD, and TB Prevention, CDC.

Corresponding author: Francisco Averhoff, faverhoff@cdc.gov, 404-718-8501.

\section{References}

1. Acharya SK. This is hepatitis: know it, confront it. Indian J Med Res 2013;138:8-10.

2. John TJ, Dandona L, Sharma VP, Kakkar M. Continuing challenge of infectious diseases in India. Lancet 2011;377:252-69.
}

3. Batham A, Gupta MA, Rastogi P, Garg S, Sreenivas V, Puliyel JM. Calculating prevalence of hepatitis B in India: using population weights to look for publication bias in conventional meta-analysis. Indian J Pediatr 2009;76:1247-57.

4. Mukhopadhyaya A. Hepatitis C in India. J Biosci 2008;33:465-73.

5. Suresh K. Integrated Diseases Surveillance Project (IDSP) through a consultant's lens. Indian J Public Health 2008;52:136-43.

6. The World Bank. Report no: ICR2203. Implementation completion and results report; 2012. Available at http://www-wds.worldbank.org/external/ default/WDSContentServer/WDSP/IB/2012/12/09/000333037_2012 1209234709/Rendered/PDF/NonAsciiFileName0.pdf.

7. Mathur P, Arora NK. Epidemiological transition of hepatitis A in India: issues for vaccination in developing countries. Indian J Med Res 2008;128:699-704. 


\section{Severe Illness from Methyl Bromide Exposure at a Condominium Resort - U.S. Virgin Islands, March 2015}

Prathit A. Kulkarni, MD ${ }^{1}$; Mary Anne Duncan, DVM²; Michelle T. Watters, MD, PhD 3 ; Leah T. Graziano ${ }^{3}$; Elena Vaouli, MPH ${ }^{3}$; Larry F. Cseh, MS²; John F. Risher, $\mathrm{PhD}^{2}$; Maureen F. Orr, MS²; Tai C. Hunte-Ceasar, $\mathrm{MD}^{4}$; Esther M. Ellis, $\mathrm{PhD}^{4}$ (Author affiliations at the end of text)

On March 22, 2015, the Agency for Toxic Substances and Disease Registry (ATSDR) was notified by the U.S. Environmental Protection Agency (EPA) of four cases of suspected acute methyl bromide toxicity among family members vacationing at a condominium resort in the U.S. Virgin Islands. Methyl bromide is a pesticide that has been banned in the United States for use in homes and other residential settings. An investigation conducted by the U.S. Virgin Islands Department of Health (VIDOH), the U.S. Virgin Islands Department of Planning and Natural Resources (DPNR), and EPA confirmed that methyl bromide had been used as a fumigant on March 18 in the building where the family had been residing, 2 days before they were transported to the hospital; three family members had life-threatening illness. On March 25, 2015, a stop-use order for methyl bromide was issued by DPNR to the pest control company that had performed the fumigation. Subsequent investigation revealed that previous fumigation with methyl bromide had occurred on October 20, 2014, at the same condominium resort. In addition to the four ill family members, 37 persons who might have been exposed to methyl bromide as a result of the October 2014 or March 2015 fumigations were identified by VIDOH and ATSDR. Standardized health questionnaires were administered to 16 of the 20 persons for whom contact information was available; six of 16 had symptoms consistent with methyl bromide exposure, including headache and fatigue. Pest control companies should be aware that use of methyl bromide is banned in homes and other residential settings, and clinicians should be aware of the toxicologic syndrome that exposure to methyl bromide can cause.

\section{IIIness Cluster Identification and Background}

On March 20, 2015, a family of four vacationing in the U.S. Virgin Islands was transported to a hospital with a 24-hour history of progressive neurologic symptoms, including generalized weakness, severe myoclonus, fasciculations, altered sensorium, and word-finding difficulty. Three of the four patients had vomiting and diarrhea; three required endotracheal intubation and mechanical ventilation.

Initial clinical suspicion included organophosphate toxicity and ciguatera fish poisoning; however, other persons who had consumed the same food as the patients had not become ill. Because chemical toxicity was considered as a possible etiology for the family's illness, management at the condominium resort where the family had been residing was contacted. A preliminary investigation revealed that an unoccupied housing unit below the one in which the family had been staying, but in the same building, had been fumigated with the pesticide methyl bromide on March 18, 2 days before the family sought medical care. The patients' neurologic syndrome was consistent with acute methyl bromide toxicity.

The family consisted of two teens and two adults, with an age range from 14 to 49 years. All four patients were treated with benzodiazepines, phenobarbital, and propofol for sedation and symptom control. The two teens were treated with the neuromuscular blocking agent rocuronium because of symptom severity, and the two adults received pralidoxime because of the initial suspicion of possible organophosphate toxicity. All four patients underwent two hemodialysis procedures when methyl bromide toxicity became the leading diagnostic consideration. Serum bromide levels of the patients obtained on March 20, the day the family was taken to the hospital, ranged from $<10 \mathrm{mg} / \mathrm{dL}^{*}$ to $13.6 \mathrm{mg} / \mathrm{dL}$ (of note, three of four specimens for bromide level determination were obtained after initiation of dialysis).

Within 3 days, all four patients were transferred to hospitals in the continental United States for further care. As of June 30, all four patients had been discharged from acute-care hospitals. Three of the four patients were receiving inpatient physical rehabilitation for significant neurologic dysfunction.

Methyl bromide was first reported to be effective as a pesticide in 1932, and was first registered for use as such in the United States in 1961 (1). Currently, its primary use is in agricultural settings for soil fumigation and in greenhouses, warehouses, and ships (2). Beginning in 1993, on the basis of the U.S. Clean Air Act and the Montreal Protocol on Substances that Deplete the Ozone Layer (1992), use of methyl bromide in the United States was set at 1991 baseline levels (3). During 1999-2005, a gradual and planned reduction in the use of methyl bromide because of its ozone-depleting properties was implemented. Certain exemptions for the use of methyl bromide are permitted, including a critical-use exemption and a quarantine and preshipment exemption; neither of these

\footnotetext{
${ }^{*}$ Values of $<10 \mathrm{mg} / \mathrm{dL}$ are beyond the validated reporting limit of the particular assay that was used to determine serum bromide levels.
} 
exemptions, however, allows for the use of methyl bromide in residential settings.

Mild symptoms from acute inhalational exposure to methyl bromide include headache, malaise, generalized weakness, and nausea; more severe manifestations of acute inhalational exposure include tremors, myoclonus, altered mental status, seizures, respiratory symptoms, and renal failure (4). Symptoms from acute inhalational exposure generally appear within 48 hours (4). During 1899-1981, a total of 115 fatal and 843 nonfatal cases of methyl bromide toxicity were reported worldwide (5). In general, with inhalational exposure, appearance of clinical symptoms depends on the air concentration of methyl bromide to which a person is exposed and the duration of exposure at that particular level. The EPA Office of Pesticide Programs considers acute inhalational exposure to methyl bromide for 1 day to be of concern at the following levels: $\geq 0.33$ parts per million (ppm) for a 24-hour time-weighted average in nonoccupational settings and $\geq 1 \mathrm{ppm}$ for an 8 -hour timeweighted average in occupational settings ( $\sigma$ ).

Methyl bromide exposure can be evaluated by measuring the bromide ion level in serum. However, detected levels of bromide ion do not always correlate with the presence or severity of clinical symptoms. A bromide level of $<1.5 \mathrm{mg} / \mathrm{dL}$ is considered normal ( 7$).^{\dagger}$ Levels as high as $8 \mathrm{mg} / \mathrm{dL}$ have been detected in the absence of overt clinical signs or symptoms ( 7 ). Conversely, one report documented chronic toxicity at serum levels as low as $4.4 \mathrm{mg} / \mathrm{dL}(8)$.

\section{Investigation and Public Health Response}

After methyl bromide had been identified as the likely cause of the patients' symptoms, both the fumigated lower unit and the upper unit in which the family had been residing were immediately sealed off. No other housing units were in the building. An assessment by DPNR and EPA confirmed that only methyl bromide had been used for fumigation. Sampling results from EPA taken on March 24 revealed the air concentration of methyl bromide to be $1.12 \mathrm{ppm}$ in the upper housing unit; on March 27, the concentration was $0.59 \mathrm{ppm}$ in the lower housing unit. Although these levels are elevated, it is not possible to know the specific air concentration of methyl bromide the family had been exposed to during March 18-20, because sampling was not done at the time fumigation was performed. An investigation by DPNR and EPA revealed that methyl bromide had also been used at the same condominium complex by the same pest control company on October 20, 2014, in four additional housing units. Air measurements were unavailable for the October 2014 fumigation. As a result of the

\footnotetext{
$\dagger$ A normal serum bromide level might not be zero because of routine exposure to a limited amount of bromide from diet, medications, or other sources.
}

investigation, on March 25, 2015, DPNR issued an immediate stop-use order to the pest control company that had performed the fumigations; the stop-use order prevented any further use of methyl bromide by the company in any setting in the U.S. Virgin Islands. EPA, in coordination with DPNR and VIDOH, subsequently performed monitoring and ventilation of the building fumigated in March 2015.

VIDOH and ATSDR, working with EPA and condominium management, sought to identify persons in addition to the affected family who had potentially been exposed to methyl bromide at the condominium resort to more fully characterize health effects of the fumigations. The identification process included any person who had been inside a fumigated building during the 2 weeks following the date of fumigation (or until the building was sealed off in the case of the March 2015 fumigation). This 2-week time frame was based on two primary considerations: 1 ) preliminary results of environmental sampling over time; and 2) expected decreases in the air concentration of methyl bromide in the affected housing units and in the associated risk of adverse health effects $(6,9)$. Potentially exposed persons included pest control company personnel, emergency responders, condominium staff members, and resort residents, vacationers, and visitors. A standardized questionnaire was used to interview exposed persons about possible exposure-related health effects.

\section{Other Potential Exposures}

In addition to the family of four, 37 persons were identified who had potentially been exposed to methyl bromide; 11 were potentially exposed after the March 2015 fumigation, 20 after the October 2014 fumigation, and one during both periods. Whether the remaining five persons were exposed during one or both periods is unknown. Contact information was unavailable for 17 of the 37 persons; among the 20 for whom contact information was available, 16 were surveyed. Of the 16, eight had been exposed after the March 2015 fumigation, seven after the October 2014 fumigation, and one during both periods.

No persons exposed only after the October 2014 fumigation reported any adverse health effects. Among the eight persons exposed after the March 2015 fumigation and the one person exposed during both periods, six had postexposure symptoms. Among these nine persons, maximum exposure time was approximately 75 minutes after the March 2015 fumigation. All six persons who had symptoms reported headache, and four reported fatigue. One person had shortness of breath, and another had a cough. All symptoms resolved within 3 weeks of exposure except for certain symptoms experienced by two persons, one who had a persistent mild headache and another who had a mild cough that had been present before the exposure occurred. Four of the six persons who had postexposure 
symptoms were emergency responders. In addition, four exposed persons had serum levels of bromide measured on March 23, 2015, 3 days after their exposure; bromide ion values ranged from $<10 \mathrm{mg} / \mathrm{dL}$ to $15.3 \mathrm{mg} / \mathrm{dL}$. Three of these four persons had symptoms.

\section{Discussion}

Methyl bromide toxicity has become less common after the use of methyl bromide began to be curtailed during the 1990s; the most recent report of methyl bromide toxicity was published in 2011 (8). However, systematic surveillance for methyl bromide toxicity does not occur on a national level, so it is difficult to know if cases have not occurred or have not been recognized or reported.

This investigation serves as a reminder to clinicians to consider the possibility of acute chemical toxicity in the relevant clinical and epidemiologic situation (e.g., an isolated family of four with rapid progression of a distinct clinical syndrome). Prompt identification of such an exposure, as occurred in this situation, can prevent further exposure and subsequent illness. Interpretation of bromide levels should be undertaken cautiously and with the assistance of personnel trained in toxicology or occupational health because of limitations of certain types of bromide testing and the lack of direct correlation between bromide levels and the presence and severity of clinical symptoms.

This investigation also highlights the public health consequences of methyl bromide use in a residential setting. Certain unsuspecting persons were exposed to this highly toxic chemical because of its nonpermitted use. Of note, most persons who experienced postexposure symptoms were emergency responders to the scene. At the time they responded, a chemical exposure was not known to be the definitive cause of the family's illness. However, if a toxic chemical release is ever identified, subsequent prompt notification of potentially exposed emergency responders is recommended.

Use of methyl bromide is restricted to specified settings as required by U.S. law and international regulations. Pest control companies should be aware of all rules regarding products they use and should ensure that all staff members receive proper education and training for application of these products in a safe manner, including use of personal protective equipment and appropriate signage. In addition, pest control companies and others involved in environmental pest control should consider the use of integrated pest management, which emphasizes prevention measures and understanding of pest life cycles and the interaction of pests with their environment (10). Broadcast spraying with nonspecific pesticides is used judiciously, if at all, in integrated pest management.

\section{Summary}

What is already known on this topic?

Methyl bromide is a highly toxic pesticide which is banned in the United States for use in homes and other residential settings. Acute toxicity from methyl bromide can result in serious neurologic disease or even death.

What is added by this report?

During March 2015, a family of four vacationing in the U.S. Virgin Islands developed acute methyl bromide toxicity as a result of improper use of methyl bromide by a pest control company at a residential location. An investigation revealed that the same company had used methyl bromide at the same location 5 months earlier. Thirty-seven additional persons were identified as potentially having been exposed to methyl bromide as a result of these fumigations. Six persons, four of whom were emergency responders, developed postexposure symptoms, including headache and fatigue.

What are the implications for public health practice?

Clinicians should be alert to the possibility of chemical toxicity in the appropriate clinical and epidemiologic setting. Pest control companies should be aware of all laws and regulations surrounding the use of highly toxic chemicals. Correct safety protocols should be followed, and adequate training for applicators should be provided.

\section{Acknowledgments}

U.S. Virgin Islands Department of Planning and Natural Resources; Richard A. Nickle, MPH, Agency for Toxic Substances and Disease Registry; Neil Norrell, Paul L. Kahn, MS, Christopher Jimenez, Kelli Lucarino, Geoffrey Garrison, Cris D’Onofrio, Eric Mosher, U.S. Environmental Protection Agency; Luis Amaro, MD, Shawn Anderson, MD, Wishburne Hunte, MD, James Nelson, MD, Christopher Reeves, MD, Walter Rohloff, MD, Lawrence Semenza, DO, Jessica Wilson, MD, Roy Lester Schneider Regional Medical Center, U.S. Virgin Islands; Fred Henretig, MD, The Children's Hospital of Philadelphia.

\footnotetext{
${ }^{1}$ Epidemic Intelligence Service, CDC; ${ }^{2}$ Division of Toxicology and Human Health Sciences, Agency for Toxic Substances and Disease Registry; ${ }^{3}$ Division of Community Health Investigations, Agency for Toxic Substances and Disease Registry; ${ }^{4}$ U.S. Virgin Islands Department of Health.

Corresponding author: Prathit A. Kulkarni, pakulkarni@cdc.gov, 609-826-5964.
}

\section{References}

1. National Pesticide Information Center. Methyl bromide general fact sheet. Corvallis, OR: National Pesticide Information Center; 2000. Available at http://npic.orst.edu/factsheets/MBgen.pdf.

2. de Souza A, Narvencar KP, Sindhoora KV. The neurological effects of methyl bromide intoxication. J Neurol Sci 2013;335:36-41.

3. US Environmental Protection Agency. The phaseout of methyl bromide. Washington, DC: US Environmental Protection Agency; 2014. Available at http://www.epa.gov/ozone/mbr/index.html. 
4. Agency for Toxic Substances and Disease Registry. Medical management guidelines for methyl bromide. Atlanta, GA: US Department of Health and Human Services, Agency for Toxic Substances and Disease Registry; 2014. Available at http://www.atsdr.cdc.gov/MHMI/mmg27.pdf.

5. Alexeeff GV, Kilgore WW. Methyl bromide. Residue Rev 1983;88:101-53.

6. US Environmental Protection Agency. RED fact sheet for methyl bromide. Washington, DC: US Environmental Protection Agency, Office of Pesticide Programs; 2008. Available at http://www.epa.gov/pesticides/ reregistration/REDs/factsheets/methylbromide-fs.pdf.
7. Ryan RP, Terry CE, Leffingwell SS, eds. Toxicology desk reference, 5th ed. Vol 1-2. Philadelphia, PA: Taylor \& Francis; 2000;843.

8. CDC. Illness associated with exposure to methyl bromide-fumigated produceCalifornia, 2010. MMWR Morb Mortal Wkly Rep 2011;60:923-6.

9. National Research Council. Methyl bromide risk characterization in California. Washington, DC: The National Academies Press; 2000.

10. US Environmental Protection Agency. Integrated pest management (IPM) principles. Washington, DC: US Environmental Protection Agency; 2014 Available at http://www.epa.gov/pesticides/factsheets/ipm.htm. 


\title{
Knowledge and Attitudes Regarding Antibiotic Use Among Adult Consumers, Adult Hispanic Consumers, and Health Care Providers - United States, 2012-2013
}

 \\ (Author affiliations at end of text)
}

Appropriate antibiotic use, in particular avoidance of antibiotics for upper respiratory infections likely to be caused by viruses $(1,2)$, is a key component of efforts to slow the increase in antibiotic-resistant infections (3). Studies suggest that Hispanic consumers might differ from non-Hispanic consumers in their knowledge and attitudes regarding antibiotic use (4). To better understand health care provider and consumer knowledge and attitudes that influence antibiotic use, CDC analyzed national internet survey data collected from participants living in the United States during 2012-2013. The participants represented three groups: 1) the total population of adult consumers (all ethnicities); 2) adult Hispanic consumers; and 3) health care providers. Hispanic consumers were more likely than all consumers to believe that if they have a cold, antibiotics would help them to get better more quickly ( $48 \%$ versus $25 \%$ ), and more likely to obtain antibiotics not prescribed by a clinician, such as antibiotics left over from a previous illness (25\% versus 9\%), obtained from a neighborhood grocery store ( $23 \%$ versus $5 \%$ ), or obtained from a friend or family member (17\% versus $6 \%)$. Most providers surveyed (54\%) reported that they believed their patients expect antibiotics during visits for a cough or cold, whereas $26 \%$ of all consumers reported this expectation. To maximize knowledge about appropriate antibiotic use among outpatients in the United States, public health initiatives should target Hispanic as well as general audiences.

Porter Novelli, a public relations firm, administers national surveys (conducted online since 2011) to health care providers and adult consumers living in the United States to assess health-related knowledge and attitudes. Questions pertaining to antibiotic use in the setting of cough or cold were included in the Summer 2012 HealthStyles and Fall 2013 HealthStyles surveys (all consumers), the 2013 Estilos survey (Hispanic consumers), and the 2012 DocStyles survey (providers).

HealthStyles survey participants were recruited from market research firm GfK's Knowledge Panel (http://www.gfk.com/ us/Solutions/consumer-panels/Pages/GfK-KnowledgePanel. aspx), which uses both random-digit-dialed and address-based sampling methods to reach potential participants (laptop computer and Internet access are provided to participants if needed). Estilos survey participants were recruited via the
QueOpinas (http://www.offerwise.com) research panel, which uses television advertisements in both English and Spanish to recruit panel members. Estilos survey questions were written in English and translated into Spanish; both language versions were available to Estilos participants. HealthStyles responses were weighted using U.S. Current Population Survey data (http://www.bls.gov/cps/) and Estilos responses were weighted using U.S. Census American Community Survey data (http:// www.census.gov/programs-surveys/acs/) to match U.S. proportions according to sex, age, household income, household size, education, census region. HealthStyles responses were also weighted by race/ethnicity, metropolitan statistical area, and internet access; Estilos responses were also weighted by country of origin and acculturation status (based on years living in the United States, language spoken at home, cultural selfidentification, and use of Spanish language media). DocStyles survey participants were recruited from the Epocrates Honors and Epocrates Allied Health panels. Surveyed providers were primary care physicians and nurse practitioners. Eligibility criteria for providers included an active individual, group, or hospital-based practice in the United States, and at least 3 years of work experience. Physician participants mirrored the American Medical Association master file proportions for age, sex, and region. Survey respondents were reimbursed for time and effort with nominal cash or cash-equivalent awards.

Surveys were distributed to 4,703 U.S. consumers in 2012 (response rate $=86 \% ; \mathrm{n}=4,044), 4,420$ U.S. consumers in 2013 (response rate $=79 \% ; n=3502$ ), 2,609 Hispanic consumers (response rate $=38 \% ; n=1,000$ ), and 3,149 health care providers (response rate $=48 \%, \mathrm{n}=1,503$, including 1,001 adult and family physicians, 252 nurse practitioners, and 250 pediatricians). Responses to questions asked of all consumers and Hispanic consumers were compared.

Responses among Hispanic consumers differed markedly from those among all consumers (Table 1). Hispanic consumers were more likely to agree that when they have a cold, antibiotics prevent more serious illness ( $40 \%$ versus 17\%) and help them get better more quickly ( $48 \%$ versus $25 \%$ ). Hispanic consumers were also more likely to report obtaining antibiotics from sources other than their doctor or clinic, including leftover antibiotics from a prior illness ( $25 \%$ versus $9 \%)$; from a 
TABLE 1. Knowledge and attitudes about antibiotic use among Hispanic consumers compared with all consumers - United States, 2012-2013*

\begin{tabular}{|c|c|c|c|}
\hline Question/Responses & $\begin{array}{c}\text { Hispanic } \\
\text { consumers } \\
(\%)\end{array}$ & $\begin{array}{c}\text { All } \\
\text { consumers } \\
(\%)\end{array}$ & $\begin{array}{l}\text { Percentage } \\
\text { point } \\
\text { difference }\end{array}$ \\
\hline When I have a cold, I should take antibiotics to prevent getting a more serious illness. * & $(40)^{\dagger \dagger}$ & $(17)^{\dagger+}$ & (23) \\
\hline When I have a cold, antibiotics help me to get better more quickly.** & $(48)^{\dagger \dagger}$ & $(25)^{\dagger \dagger}$ & (23) \\
\hline \multicolumn{4}{|l|}{ Which of the following side effects are common after taking an antibiotic?§§ } \\
\hline Nausea/Vomiting & $(22)$ & $(22)$ & (0) \\
\hline Diarrhea & (21) & (35) & (14) \\
\hline Abdominal or stomach pain & (19) & $(22)$ & (3) \\
\hline Headache & (15) & $(10)$ & (5) \\
\hline Rash & $(12)$ & (14) & (2) \\
\hline None of these & (27) & (16) & (11) \\
\hline Don't know & (25) & $(40)$ & (15) \\
\hline \multicolumn{4}{|l|}{ If you get antibiotics from sources other than your doctor or clinic, where do you get them?§§ } \\
\hline Leftover from being sick before & (25) & (9) & (16) \\
\hline Neighborhood grocery store & (23) & (5) & (18) \\
\hline Family member or friend & (17) & (6) & (11) \\
\hline From another country & (8) & (2) & (6) \\
\hline Internet pharmacy & (7) & (1) & (6) \\
\hline Some other source not listed & (7) & (3) & (4) \\
\hline I have never done this & (46) & (80) & (34) \\
\hline \multicolumn{4}{|l|}{ What do you expect of your provider during a visit for cough or cold?** } \\
\hline Suggestions for symptom relief & (58) & (35) & (23) \\
\hline An antibiotic & (41) & (26) & (15) \\
\hline Rule out something worse/Reassurance & (31) & (42) & (11) \\
\hline Other & $(2)$ & (3) & $(1)$ \\
\hline None of these & (5) & (16) & $(11)$ \\
\hline Not sure & (6) & (15) & (9) \\
\hline
\end{tabular}

* Based on 2013 Estilos survey (Hispanic consumers) and Summer 2012 HealthStyles and Fall 2013 HealthStyles surveys (all consumers). Individual consumer response numbers are not reported because percentages have been weighted to be nationally representative.

${ }^{+} \mathrm{n}=1,000$.

$\S \mathrm{n}=4,044$ (Summer 2012 HealthStyles survey) and $\mathrm{n}=3,502$ (Fall 2013 HealthStyles survey).

" Because of the large sample sizes, p-values are not reported.

* Data on all consumers are from the Summer 2012 HealthStyles survey.

t+ Percentages reflect those who reported they agreed with the statement.

$\S \S$ Data on all consumers are from the Fall 2013 HealthStyles survey.

neighborhood grocery store ( $23 \%$ versus $5 \%$ ); or from a family member or friend (17\% versus 6\%). Although knowledge of antibiotic side effect profiles was generally comparable between Hispanic consumers and all consumers, Hispanic consumers were less aware of potential dangers of antibiotic use, such as antibiotics becoming less effective after their use (antibiotic resistance) or that antibiotics might kill the "good" bacteria the body needs.

Fifty-four percent of providers perceived that patients expect an antibiotic at a visit for a viral illness (Table 2); $26 \%$ of all consumers and $41 \%$ of Hispanic consumers reported expecting an antibiotic at a visit for a cough or cold (Table 1). However, despite the substantial percentage of consumers in both groups reporting the expectation of an antibiotic, all consumers most commonly expected reassurance (42\%) and Hispanic consumers most commonly expected suggestions for symptom relief (58\%). Providers were most commonly deterred from prescribing antibiotics because of the potential for antibiotic resistance $(94 \%)$ and side effects or allergic reactions (71\%), and most commonly considered experience with the drug (85\%), cost $(84 \%)$, and side effect profile $(81 \%)$ when deciding which antibiotic to prescribe (Table 2).

\section{Discussion}

Health care providers face ongoing challenges in responding to patient expectations regarding antibiotic use. Antibiotics are rarely indicated for a cough or cold $(1,2)$, but $41 \%$ of Hispanic consumers and more than a quarter of all consumers reported expecting an antibiotic at a health care visit for these syndromes. More than half of providers reported that their patients expect an antibiotic prescription. Provider perception of patient expectations for an antibiotic is important, because it has been shown to be a reliable predictor of overprescribing (5-7), which might contribute to preventable side effects, adverse drug events and antibiotic resistance. However, the fact that consumers were more likely to expect reassurance (all consumers) or suggestions for symptom relief (Hispanic 
TABLE 2. Knowledge and attitudes about antibiotics and antibiotic resistance among health care providers - United States, 2012*

\begin{tabular}{lc}
\hline Question/Responses & $\begin{array}{c}\text { Health care } \\
\text { providers } \\
\text { ( }\end{array}$ \\
\hline What do parents/patients expect of you during a visit for a viral illness? \\
Symptom relief recommendation/OTCs & $(77)$ \\
Rule out secondary infection/reassurance & $(72)$ \\
An antibiotic & $(54)$ \\
None of these & $(<1)$ \\
Not sure & $(2)$ \\
Which potential risks deter you from prescribing antibiotics? & \\
Antibiotics become less effective (antibiotic resistance) & $(94)$ \\
Side effects and allergic reactions & $(71)$ \\
May kill “good" bacteria that your body needs & $(58)$ \\
None of these & $(2)$ \\
Not sure & $(<1)$ \\
When you prescribe an antibiotic, which of the following do you consider \\
when deciding which antibiotic to prescribe? \\
Experience prescribing that drug & $(85)$ \\
Cost & $(84)$ \\
Side effect profile & $(81)$ \\
Guidelines/Literature & $(74)$ \\
Convenient dosing & $(73)$ \\
Patient request & $(23)$ \\
Pharmaceutical sales representative information & $(6)$ \\
Other & $(4)$ \\
None of these & $(0)$ \\
Do not prescribe antibiotics & $(1)$ \\
\hline Abbrevion: & \\
\hline
\end{tabular}

Abbreviation: OTCs = over-the-counters (i.e., drugs available without a prescription). * Based on 2012 DocStyles survey (health care providers).

${ }^{+} \mathrm{n}=1,503$.

consumers) suggests that provider counseling, rather than an antibiotic prescription, is paramount in consumer satisfaction.

Knowledge about the effectiveness of antibiotics in the setting of a cough or cold was limited among both consumer populations, but particularly among Hispanic consumers. Hispanic consumers were almost three times more likely than all consumers to report obtaining antibiotics from a source other than a clinic or pharmacy with a prescription from a health care provider. These results are consistent with findings from previous regional studies, which reported that, compared with non-Hispanic whites, Hispanic consumers were less knowledgeable about indications for antibiotic use, were more frequently dissatisfied if antibiotics were not prescribed (8), and commonly obtain antibiotics without a prescription $(4,9)$. Despite federal laws mandating prescriptions, antibiotics might be readily available over the counter in some locally owned grocery stores serving Hispanic communities $(6,10)$. Self-administration of antibiotics is concerning, as it might result in a lack of appropriate care for those who avoid seeing a provider, and might also lead to increased antibiotic resistance in areas with over-the-counter antibiotic availability.

The findings in this report are subject to at least five limitations. First, despite efforts to reach consumers from all social strata, potential participants without a phone line, stable

\begin{abstract}
Summary
What is already known on this topic?

Antibiotic resistance is a growing public health concern. Appropriate antibiotic use is a key strategy to address increases in antibiotic-resistant infections. Consumers' and providers' knowledge and attitudes toward antibiotic use influence their expectations and prescribing behaviors.

What is added by this report?

Hispanic consumers in the United States are almost twice as likely as consumers overall to believe that taking antibiotics lessens the symptoms of a cold, and almost three times as likely to obtain antibiotics not prescribed by a clinician, such as antibiotics left over from a previous illness. Fifty-four percent of surveyed health care providers think their patients expect antibiotics during visits for a cough or cold; $26 \%$ of surveyed consumers report having this expectation.

What are the implications for public health practice?

Consumer education needs to emphasize both the limited circumstances in which respiratory infections require an antibiotic and the individual and population-level harms of inappropriate antibiotic use. Public health initiatives might target Hispanic as well as general audiences and consider cultural differences in health knowledge and attitudes, for example, through the use of culturally appropriate materials made available in both English and Spanish.
\end{abstract}

address, or sufficient literacy were likely excluded, resulting in a biased sample. Second, low survey response rates, particularly among Hispanic consumers and providers, might further have contributed to selection bias. Third, unweighted data demonstrated that participants in the all-consumer sample were disproportionately white/non-Hispanic and educated compared with the general population; Hispanic consumer respondents were younger, more educated, and had lower household income than the national Hispanic population; and provider respondents were disproportionately male and from the Northeast and West regions of the United States. Fourth, the sample of all consumers included Hispanic respondents (accounting for $13.3 \%$ and $14.1 \%$ of the weighted responses in the 2012 HealthStyles and 2013 HealthStyles surveys, respectively), which might underestimate the magnitude of differences between Hispanic and non-Hispanic groups. Finally, important differences might exist between Hispanic subgroups (based on acculturation status or ethnic origin) that were not captured in this study.

Appropriate antibiotic use is important to limit unnecessary adverse drug events and development of antibiotic resistance. The differences in health knowledge and attitudes between Hispanic and all consumers observed in this study underscore the importance of considering cultural factors in public health messaging about appropriate antibiotic use. Research is needed 
to investigate the influence of specific cultural factors, such as immigration status, country of origin, and degree of acculturation, on health knowledge and attitudes among Hispanic as well as other minority populations. Public health initiatives have traditionally focused on the patient-provider relationship as a framework to disseminate educational messages and interventions. However, these approaches might miss consumers who use antibiotics not prescribed for them. Complementary interventions that improve access to health care, particularly among recent immigrants who might face the steepest barriers to receiving health care, might also help reduce antibiotic self-administration (4).

Patient expectations for antibiotics and provider perceptions of these expectations highlight the ongoing need for consumer education and improvement of patient-provider communication to maximize judicious antibiotic prescribing. CDC's "Get Smart: Know When Antibiotics Work" program (http:// www.cdc.gov/GetSmart/Community) distributes culturally appropriate materials in both English and Spanish to assist providers in communicating with patients about when and why antibiotics are indicated.

\footnotetext{
${ }^{1}$ Epidemic Intelligence Service, CDC; ${ }^{2}$ Division of Bacterial Diseases, National Center for Immunization and Respiratory Diseases, CDC.

Corresponding author: Louise K. Francois Watkins, LFrancoisWatkins@cdc.gov, 404-639-4755.
}

\section{References}

1. Grijalva CG, Nuorti JP, Griffin MR. Antibiotic prescription rates for acute respiratory tract infections in US ambulatory settings. JAMA 2009;302:758-66.

2. Fairlie T, Shapiro DJ, Hersh AL, Hicks LA. National trends in visit rates and antibiotic prescribing for adults with acute sinusitis. Arch Intern Med 2012;172:1513-4.

3. CDC. Antibiotic resistance threats in the United States, 2013. Atlanta, GA: US Department of Health and Human Services, CDC; 2014. Available at http://www.cdc.gov/drugresistance/threat-report-2013/pdf/ ar-threats-2013-508.pdf.

4. Céspedes A, Larson E. Knowledge, attitudes, and practices regarding antibiotic use among Latinos in the United States: review and recommendations. Am J Infect Control 2006;34:495-502.

5. Macfarlane J, Holmes W, Macfarlane R, Britten N. Influence of patients' expectations on antibiotic management of acute lower respiratory tract illness in general practice: questionnaire study. BMJ 1997;315:1211-4.

6. Coenen S, Michiels B, Renard D, Denekens J, Van Royen P. Antibiotic prescribing for acute cough: the effect of perceived patient demand. $\mathrm{Br}$ J Gen Pract 2006;56:183-90.

7. Mangione-Smith R, McGlynn EA, Elliott MN, Krogstad P, Brook RH. The relationship between perceived parental expectations and pediatrician antimicrobial prescribing behavior. Pediatrics 1999;103:711-8.

8. Corbett KK, Gonzales R, Leeman-Castillo BA, Flores E, Maselli J, Kafadar K. Appropriate antibiotic use: variation in knowledge and awareness by Hispanic ethnicity and language. Prev Med 2005;40:162-9.

9. Mainous AG 3rd, Cheng AY, Garr RC, Tilley BC, Everett CJ, McKee MD. Nonprescribed antimicrobial drugs in Latino community, South Carolina. Emerg Infect Dis 2005;11:883-8.

10. Larson E, Lin SX, Gomez-Duarte C. Antibiotic use in Hispanic households, New York City. Emerg Infect Dis 2003;9:1096-102. 


\section{Death Following Ingestion of an Edible Marijuana Product - Colorado, March 2014}

Jessica B. Hancock-Allen, MSN ${ }^{1,2}$; Lisa Barker²; Michael VanDyke, $\mathrm{PhD}^{2}$; Dawn B. Holmes, $\mathrm{MD}^{3}$ (Author affiliations at end of text)

In March 2014, the Colorado Department of Public Health and Environment (CDPHE) learned of the death of a man aged 19 years after consuming an edible marijuana product. CDPHE reviewed autopsy and police reports to assess factors associated with his death and to guide prevention efforts. The decedent's friend, aged 23 years, had purchased marijuana cookies and provided one to the decedent. A police report indicated that initially the decedent ate only a single piece of his cookie, as directed by the sales clerk. Approximately 30-60 minutes later, not feeling any effects, he consumed the remainder of the cookie. During the next 2 hours, he reportedly exhibited erratic speech and hostile behaviors. Approximately 3.5 hours after initial ingestion, and 2.5 hours after consuming the remainder of the cookie, he jumped off a fourth floor balcony and died from trauma. The autopsy, performed 29 hours after time of death, found marijuana intoxication as a chief contributing factor. Quantitative toxicologic analyses for drugs of abuse, synthetic cannabinoid, and cathinones ("bath salts") were performed on chest cavity blood by gas chromatography and mass spectrometry. The only confirmed findings were cannabinoids $(7.2 \mathrm{ng} / \mathrm{mL}$ delta-9 tetrahydrocannabinol [THC] and $49 \mathrm{ng} / \mathrm{mL}$ delta- 9 carboxy-THC, an inactive marijuana metabolite). The legal whole blood limit of delta-9 THC for driving a vehicle in Colorado is $5.0 \mathrm{ng} / \mathrm{mL}$. This was the first reported death in Colorado linked to marijuana consumption without evidence of polysubstance use since the state approved recreational use of marijuana in 2012.

According to the police report, the decedent had been marijuana-naïve, with no known history of alcohol abuse, illicit drug use, or mental illness. In addition to listing inactive ingredients, the cookie label described the psychoactive ingredients as " $65 \mathrm{mg} \mathrm{THC/6.5} \mathrm{servings} \mathrm{(THC,} \mathrm{tetrahydrocan-}$ nabinol, the principal psychoactive agent in cannabis)." The label also noted, "This marijuana product has not been tested for contaminants or potency." According to the police report, the sales clerk had instructed the buyer and decedent to divide each cookie into sixths, each piece containing approximately $10 \mathrm{mg}$ of THC, the serving size, and to ingest one serving at a time. The police report did not indicate whether the sales clerk provided specific instructions for how long to wait between ingesting each serving.
This case illustrates a potential danger associated with recreational edible marijuana use. Some studies have suggested an association between cannabis and psychological disturbances (1). Second to alcohol, marijuana is the most commonly used recreational drug in the United States, with an estimated 19.8 million past-month users during 2013 (2). In 2012, Colorado and Washington became the first states to permit recreational use of marijuana under their state laws (3). The first state-licensed recreational marijuana stores in Colorado opened in January 2014. An estimated 45\% of Colorado's marijuana sales involve edible marijuana, including THC-infused food, drink, and pills $(4,5)$. Colorado's marijuana surveillance system collects adverse outcomes data from hospitalizations, emergency department visits, and poison center calls.

Systemic THC levels and psychoactive effects after ingestion are highly variable because of differences in bioavailability, rate of gastrointestinal absorption, and metabolic first-pass effect whereby an orally administered drug is partially metabolized (principally in the liver) before reaching systemic distribution $(6,7)$. Because absorption is slower, the onset of effects is delayed (with mean peak plasma concentration at 1-2 hours after ingestion, in contrast with 5-10 minutes to peak plasma concentrations if smoked), and duration of intoxication is longer when THC is ingested compared with when it is smoked (7). Whereas a single-serving recreational edible marijuana dose in Colorado was set at $10 \mathrm{mg}$ of THC, multiple-dose recreational edible products, often containing $100 \mathrm{mg}$ of THC, were available during March 2014 (4). The marijuana store where the implicated cookies had been purchased voluntarily gave all 67 remaining cookies of the same brand to the Denver Police Department. Testing confirmed that the THC levels in the items were within required limits. Because of the delayed effects of THC-infused edibles, multiple servings might be consumed in close succession before experiencing the "high" from the initial serving, as reportedly occurred in this case. Consuming a large dose of THC can result in a higher THC concentration, greater intoxication, and an increased risk for adverse psychological effects.

Recreational marijuana is now permitted for persons aged $\geq 21$ years under state law in four states (Alaska, Colorado, Oregon, and Washington) and the District of Columbia; marijuana-attributed morbidity and mortality surveillance can help guide efforts to prevent overconsumption in these jurisdictions. Regulation of recreational marijuana edibles in Colorado continues to evolve. On the basis of initial surveillance data in Colorado and numerous cases of accidental 
overconsumption, on February 1, 2015, Colorado instituted new packaging and labeling rules, requiring that recreational edible marijuana products contain no more than $10 \mathrm{mg}$ of THC, or have clear demarcation of each 10-mg serving (8). In addition, before distribution, cannabinoid potency testing is now performed on batches of recreational edible marijuana products by state-certified laboratories. Other states permitting recreational marijuana use could potentially reduce adverse health effects by considering similar THC limits in marijuana edible products, and by enforcing clear labeling standards that require information on multidose products. Although the decedent in this case was advised against eating multiple servings at one time, he reportedly consumed all five of the remaining servings of the THC-infused cookie within 30-60 minutes after the first serving, suggesting a need for improved public health messaging to reduce the risk for overconsumption of THC.

${ }^{1}$ Epidemic Intelligence Service, CDC; ${ }^{2}$ Colorado Department of Public Health and Environment; ${ }^{3}$ Denver Office of the Medical Examiner.

Corresponding author: Jessica Hancock-Allen, ydi3@cdc.gov, 303-692-2745.

\section{References}

1. Radhakrishnan R, Wilkinson ST, D'Souza DK. Gone to pot-a review of the association between cannabis and psychosis. Front Psychiatry 2014;5:54.

2. Substance Abuse and Mental Health Services Administration. Results from the 2013 National Survey on Drug Use and Health: summary of national findings. Rockville, MD: US Department of Health and Human Services, Substance Abuse and Mental Health Services Administration; 2014. NSDUH Series H-48. Available at http://www.samhsa.gov/ data/sites/default/files/NSDUHresultsPDFWHTML2013/Web/ NSDUHresults2013.pdf.

3. Colorado Department of Revenue. Laws: constitution, statues and regulationsmarijuana enforcement. Available at https:/www.colorado.gov/pacific/ enforcement/laws-constitution-statutes-and-regulations-marijuana-enforcement.

4. Marijuana Enforcement Division, Colorado Department of Revenue. Permanent rules related to the Colorado retail marijuana code. 1 CCR 212-2. Available at https://www.colorado.gov/pacific/sites/default/files/ Retail\%20Marijuana\%20Rules, \%20Adopted\%20090913,\%20 Effective\%20101513\%5B1\%5D_0.pdf.

5. IngoldJ. Proposed Colorado marijuana edibles ban shows lingering pot discord. The Denver Post. October 20, 2014. Available at http://www.denverpost.com/news/ ci_26765732/proposed-colorado-marijuana-edibles-ban-shows-lingering-pot.

6. Huestis MA. Human cannabinoid pharmacokinetics. Chem Biodivers 2007;4:1770-804.

7. Perez-Reyes M, Lipton MA, Timmons MC, Wall ME, Brine DR, Davis KH. Pharmacology of orally administered 9-tetrahydrocannabinol. Clin Pharmacol Ther 1973;14:48-55.

8. Marijuana Enforcement Division, Colorado Department of Revenue. Retail marijuana product manufacturing, packaging, and labeling compliance guidance. Available at https://www.colorado.gov/pacific/sites/ default/files/14-10_IndustryBulletin-Attachments.pdf. 


\section{Outbreak of Cryptosporidiosis Among Veterinary Medicine Students - Philadelphia, Pennsylvania, February 2015}

Lauren N. Drinkard, $\mathrm{MPH}^{1}$; Ashlee Halbritter, $\mathrm{MPH}^{1}$; Giang T. Nguyen, $\mathrm{MD}^{1}$; Patricia L. Sertich, VMD ${ }^{1}$; Max King, $\mathrm{PhD}^{1}$; Sallyann Bowman, $\mathrm{MD}^{1}$; Rebecca Huxta, $\mathrm{MPH}^{1}$; Mary Guagenti ${ }^{1}$

(Author affiliations at end of text)

On February 20, 2015, a northeastern university's student health center was notified of five veterinary medicine students with gastrointestinal symptoms. An investigation was conducted to establish the existence of an outbreak, determine the etiology, evaluate risk factors, and recommend control measures.

All five students had attended a training session at the university's bovine obstetrics laboratory on February 13, which included the handling of two euthanized calves. Patient symptoms, date of onset, and history of calf exposure suggested cryptosporidiosis. Infection with Cryptosporidium, a protozoa that causes watery diarrhea and is transmitted by infectious oocysts via the fecal-oral route (1), is common among calves (2). Symptoms in humans typically begin 7 days (range $=2-10$ days) after infection and include intermittent abdominal cramps, nausea, vomiting, fever, and weight loss, lasting approximately 1-2 weeks (3).

Two calves used in the training sessions had been euthanized and frozen at $-1.4^{\circ} \mathrm{F}\left(-17.0^{\circ} \mathrm{C}\right)$ on February 11 . Approximately 28 hours later, the calves were thawed and detergent-washed by laboratory staff in accordance with standard protocols. Necropsies were performed on both animals on February 23, and revealed Cryptosporidium oocysts on an acid-fast stain of an intestine smear from one of the calves.

Interviews revealed that 22 students had attended the training session. Sixteen students reported symptoms, including diarrhea (13 students), abdominal cramps (13), nausea (12), fatigue (eight), vomiting (seven), anorexia (five), headache (four), and chills or sweats (four), lasting 2-10 days. Among the 16 symptomatic students, the median age was 25 years (range $=24-30$ years), and 13 were female.

Four symptomatic students submitted stool specimens. One case was confirmed by detection of Cryptosporidium oocysts using direct fluorescent antibody testing; the other 15 were classified as probable cases, based on CDC case definitions (1). To account for the possibility of other infectious etiologies, stool specimens were also tested for Giardia, Cyclospora cayetanensis, Isospora, Salmonella, Shigella, Escherichia coli, and Campylobacter; all tests were negative. The positive acid-fast stain from one of the calves and one of the students with a confirmed case implicated the obstetrics laboratory as the source of the outbreak.

The bovine obstetrics laboratory personal protective equipment (PPE) protocol includes donning of gloves and coveralls before animal handling and cleaning boots and doffing of gloves and coveralls after animal handling, followed by 30 seconds of hand washing with warm water and soap. Face protection is not included in PPE protocols for this laboratory. Although all of the 22 students wore gloves during the training session, the number of students who removed their coveralls or washed their hands afterwards is unknown. At least four of the symptomatic students reported that they did not immediately doff their coveralls.

Cryptosporidiosis outbreaks have been reported among veterinary students (4), usually through contact with infected calves, and are associated with lapses in hygiene (5). In this outbreak, students were infected through contact with euthanized calves that had been frozen and thawed before the training session. Cryptosporidium oocysts can survive various environmental pressures, including extended exposures at temperatures as low as $-7.6^{\circ} \mathrm{F}\left(-22.0^{\circ} \mathrm{C}\right)$ for $>700$ hours $(6)$. This cluster highlights the importance of appropriate hygiene and proper animal cadaver handling. Since the likelihood of calves being infected with cryptosporidiosis is high, veterinary medical institutions should ensure that recommendations for PPE and proper hygiene techniques for students and staff are fully implemented.

\footnotetext{
${ }^{1}$ University of Pennsylvania.

Corresponding author: Lauren N. Drinkard, drinkard@upenn.edu, 215-746-0806.
}

\section{References}

1. CDC. National Notifiable Diseases Surveillance System (NNDSS): Cryptosporidiosis (Cryptosporidium spp.) 2012 case definition. Available at http://wwwn.cdc.gov/nndss/conditions/cryptosporidiosis/ case-definition/2012.

2. Santín M, Trout JM, Xiao L, Zhou L, Greiner E, Fayer R. Prevalence and age-related variation of Cryptosporidium species and genotypes in dairy calves. Vet Parasitol 2004;122:103-17.

3. CDC. Parasites: Cryptosporidium (also known as "Crypto"). Available at http://www.cdc.gov/parasites/crypto/illness.html.

4. Preiser G, Preiser L, Madeo L. An outbreak of cryptosporidiosis among veterinary science students who work with calves. J Am Coll Health 2003;51:213-5.

5. Gait R, Soutar RH, Hanson M, Fraser C, Chalmers R. Outbreak of cryptosporidiosis among veterinary students. Vet Rec 2008;162:843-5.

6. Robertson LJ, Campbell AT, Smith HV. Survival of Cryptosporidium parvum oocysts under various environmental pressures. Appl Environ Microbiol 1992;58:3494-500. 


\section{Age-Adjusted Death Rates* from Cancer, ${ }^{\dagger}$ by U.S. Census Region ${ }^{\S}$ and Year - United States, 1970-2013}

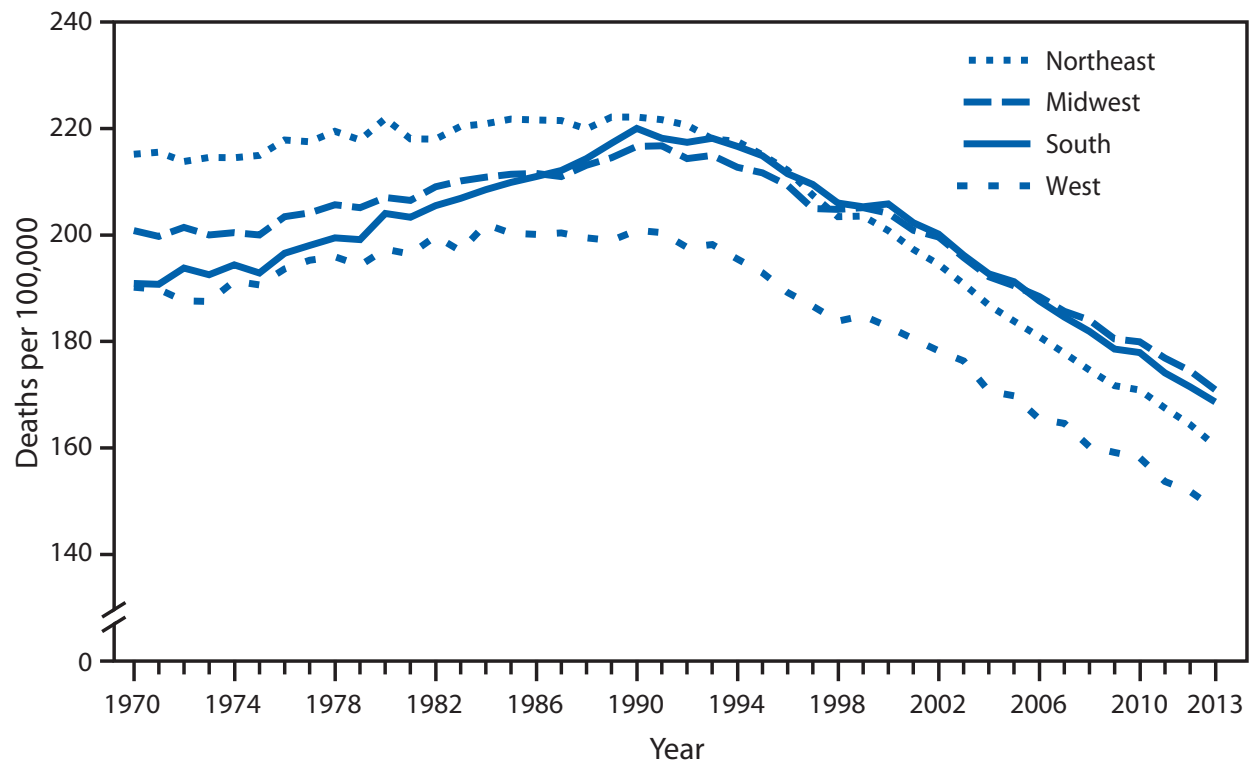

\footnotetext{
* Per 100,000 standard 2000 population.

† Cancer deaths are identified using underlying cause of death with codes 140-209 (1970-1978), 140-208 (1979-1998) and C00-C97 (1999-2013) in the International Classification of Diseases, Eighth, Ninth, and Tenth Revision.

$\S$ Northeast: Connecticut, Maine, Massachusetts, New Hampshire, Rhode Island, New Jersey, New York, Pennsylvania, and Vermont; Midwest: Illinois, Indiana, lowa, Kansas, Michigan, Minnesota, Missouri, Nebraska, North Dakota, Ohio, South Dakota, and Wisconsin; South: Alabama, Arkansas, Delaware, Florida, Georgia, Kentucky, Louisiana, Mississippi, Maryland, North Carolina, Oklahoma, South Carolina, Virginia, Tennessee, Texas, West Virginia, and District of Columbia; West: Alaska, Arizona, California, Colorado, Hawaii, Idaho, Montana, Nevada, New Mexico, Oregon, Utah, Washington, and Wyoming.
}

The age-adjusted cancer death rates increased significantly from 1970 to 1990 in each census region in the United States. The rate increased an average of $0.16 \%$ per year in the Northeast, $0.38 \%$ in the Midwest, $0.71 \%$ in the South, and $0.27 \%$ in the West. Since 1990, the rates have decreased at an ever faster rate, down on average by $1.41 \%$ in the Northeast, $1.02 \%$ in the Midwest, $1.15 \%$ in the South, and $1.30 \%$ in the West each year. At the beginning of the period, rates were highest in the Northeast, but since the late 1990s, rates in the South and Midwest have been higher. Throughout the period, the rates were lowest in the West census region.

Source: National Vital Statistics System. Mortality public use data files, 1970-2013. Available at http://www.cdc.gov/nchs/data_access/ vitalstatsonline.htm.

Reported by: Jiaquan Xu, MD, jax4@cdc.gov, 301-458-4086. 

The Morbidity and Mortality Weekly Report (MMWR) Series is prepared by the Centers for Disease Control and Prevention (CDC) and is available free of charge in electronic format. To receive an electronic copy each week, visit MMWR's free subscription page at http://www.cdc.gov/mmwr/mmwrsubscribe.html. Paper copy subscriptions are available through the Superintendent of Documents, U.S. Government Printing Office, Washington, DC 20402; telephone 202-512-1800.

Readers who have difficulty accessing this PDF file may access the HTML file at http://www.cdc.gov/mmwr/index2015.html. Address all inquiries about the MMWR Series, including material to be considered for publication, to Executive Editor, MMWR Series, Mailstop E-90, CDC, 1600 Clifton Rd., N.E., Atlanta, GA 30329-4027 or to mmwrq@cdc.gov.

All material in the MMWR Series is in the public domain and may be used and reprinted without permission; citation as to source, however, is appreciated. Use of trade names and commercial sources is for identification only and does not imply endorsement by the U.S. Department of Health and Human Services.

References to non-CDC sites on the Internet are provided as a service to $M M W R$ readers and do not constitute or imply endorsement of these organizations or their programs by CDC or the U.S. Department of Health and Human Services. CDC is not responsible for the content of these sites. URL addresses listed in $M M W R$ were current as of the date of publication.

ISSN: 0149-2195 